\title{
Narrativas de aprender, narrativas de ensinar: como venho aprendendo a ensinar artes visuais ${ }^{1}$
}

Henrique Lima Assis²

\section{Resumo}

Fundamentado em Hall (2005), Dubar (1997), Nóvoa (1992), compartilho, neste artigo, algumas experiências que marcaram o modo como venho aprendendo a ensinar artes visuais. Sendo que os espaços escolares se constituem em um dos lugares que contribuem para as minhas identificações culturais, compartilho, também, algumas reflexões oriundas da unidade temática de ensino, intitulada Olhares eletrônicos: uma experiência com a cultura visual, desenvolvida com estudantes do ensino médio, numa escola estadual de Goiânia. Então, apoiado na concepção de Sacristán (1995), os desenhos curriculares selecionam e valorizam mais certos conteúdos em relação aos demais, nesta unidade temática, selecionei o videoclipe como possibilidade de refletir sobre como vemos, como somos vistos e como somos capazes de ver a nós mesmos e o mundo.

Palavras-chave: Identificações culturais; Narrativas de aprender e ensinar; Cultura Visual; Unidade temática de ensino.

\begin{abstract}
It supported in Hall (2005), Dubar (1997), Nóvoa (1992) I shared this article some experience which marked the shape how I have been learning the to teach visual arts. Being that the pertaining to school spaces if constitute in one of the places that contribute for my cultural identifications, I share, too, some reflections are derived from thematic unit of education, it intitled Electronic looks: an experience with the visual culture, it developed with high school students, in a state school of Goiânia. Then, it supported in the conception of Sacristán (1995), the curriculum drawings select and value more certain components in relation to others, this thematic unit selects the video clip like possibility to reflect on as we see, as we are seen and as we are capable to see we ourselves and to the world.
\end{abstract}

Key words: Cultural identifications; Narratives to learn and to teach; Visual culture; Thematic unit of education

\footnotetext{
${ }^{1}$ Esta pesquisa apresenta mais uma experiência de narrar minhas vivências curriculares e como estas tem interferido nos meus processos formativos e, consequentemente, identitários.

${ }^{2}$ Licenciado em Artes Visuais pela Universidade Federal de Goiás (2003), Especialista em Métodos e Técnicas de Ensino pela Universidade Salgado de Oliveira (2005) e Mestre em Cultura Visual pela Universidade Federal de Goiás (2007). É membro do Grupo de Pesquisa em Arte, Educação e Cultura (GEPAEC) da Universidade Federal de Santa Maria (RS), da Rede I bero Americana de Educação Artística (RIAEA) e da International Society for Education Through Art (INSEA). Coordena as atividades pedagógicas do Centro de Estudo e Pesquisa Ciranda da Arte, da Secretaria de Estado da Educação de Goiás - SEDUC, tendo como atribuições pensar e promover a formação continuada dos professores de arte e integra o Núcleo de Desenvolvimento Curricular SEDUC, coordenando as discussões para a construção das Orientações Curriculares em Arte para a Educação Básica, em suas diferentes modalidades.
} 
Compreendo os processos históricos como narrativas que privilegiam a memória e, a partir da imaginação, organizam as experiências e os fatos para serem contados ou recontados, escritos ou reescritos. Esta compreensão está amparada em Bosi (2007), Benjamin (1996) e Le Goff (1996), segundo os quais a História passa a ser uma recriação, pois parte do pressuposto de que se pode reconstruir o presente, ao lançar mão de vivências do passado e buscar perspectivas no futuro.

Bosi (2007, p.55) esclarece que "lembrar não é reviver, mas refazer, reconstruir, repensar, com imagens e idéias de hoje as experiências do passado". De tal modo, tanto história quanto memória convivem no mesmo cenário temporal, só que a história é “intelectual e formal (consequentemente) usa a vestimenta acadêmica, enquanto que a memória não respeita regras nem metodologias, é afetiva e revive a cada lembrança" (BARBOSA, 2008, p. 01), entendendo que a memória é afetiva, apaixonada, seletiva, reconstrutiva e que passado, presente e futuro podem conviver, ao mesmo tempo, em nossas experiências quotidianas. Nesse sentido, algumas de minhas reflexões partem de análises sobre as transformações pelas quais os indivíduos vêm passando, influenciadas pelos efeitos da globalização, dos processos migratórios e do avanço dos meios de informação e comunicação.

De tal modo, Agier (2001), Sanchis (1996), Hall (2005), Nóvoa (1992) e outros pesquisadores consideram os processos formativos como resultado de negociações permanentes entre indivíduos e sociedade, sendo, portanto, fluidos, em construção, sempre em movimento, superando a concepção de identidade cultural como algo estável. Esses paradigmas geraram as bases dos sujeitos pós-modernos, que não possuem

[...] uma identidade fixa, essencial ou permanente. A identidade torna-se uma "celebração móvel": formada e transformada continuamente em relação às formas pelas quais somos representados ou interpelados nos sistemas culturais que nos rodeiam (HALL, 2005, p. 13).

Com base nessa concepção de constantes transformações, de rupturas contraditoriamente justapostas, de tradições assumidas ou descartadas, formamos a noção da identidade na pós-modernidade. Temos, assim, as identificações não como qualidades inatas, originais e imutáveis, mas como construções relacionais, que se configuram a partir de diferentes situações de comunicação, ou seja, um indivíduo precisa, sempre, do outro para ser referendado, imbricando relações de semelhança ou diferença, interligando dimensões pessoais e coletivas. Conforme Woodward (2006, p. 07), “a identidade é, assim, marcada pela diferença". 
Para Dubar (1997), as identidades são elaborações individuais e coletivas, a um só tempo, associadas aos processos de intervenção de fatores externos e dos indivíduos sobre si mesmos. As concepções de arte, religião, profissão, educação, por exemplo, são construídas socialmente, de acordo com os lugares/culturas em que se convive. Nesse sentido, o autor enfatiza que a identidade profissional também possui um caráter dinâmico, mutável, contraditório e que não constitui apenas uma identidade profissional, mas "também, e, sobretudo, uma projeção de si no futuro, a antecipação de uma trajetória de emprego e o desencadear de uma lógica de aprendizagem, ou melhor, de formação" (DUBAR, 1997, p. 114)

Assim, narrativas de vida e narrativas de formação estão conectadas numa grande teia de significações, ou seja, o indivíduo constrói sua identidade profissional criando ou recriando representações sobre si mesmo e sobre suas funções. Para além de uma simples reconstituição histórica, os enunciados que se seguem são resultado de um exercício carregado de autocompreensão e autoconsciência, que se tornou uma experiência singular, como a própria vida, permitindo-me visualizar quem sou e o que ainda quero e posso vir a ser.

\section{Narrativas de aprender}

Ingressei na Faculdade de Artes Visuais - FAV/UFG - em 1999, período em que o corpo docente discutia o currículo da Licenciatura para atender aos ditames da nova Lei de Diretrizes e Bases da Educação de 1996, cujo caminho era a formação específica, afinada com o novo cenário para a formação dos professores no Brasil. Feitas as alterações no currículo, a direção da Faculdade e os professores que discutiam a elaboração da nova matriz curricular, sugeriram que minha turma migrasse para o novo currículo, ou seja, da Educação Artística à Licenciatura em Artes Visuais.

A migração aconteceu e começamos a verticalizar nossos conhecimentos em arteeducação/artes visuais. A História da Arte que, anteriormente, só era ministrada nos dois primeiros anos, com caráter universal e polivalente, incluindo a História da Música, passava a ser ministrada nos quatro anos, ampliando as questões referentes às artes visuais, abarcando a História da Arte na América Latina, no Brasil e em Goiás. Verticalizamos, também, as discussões acerca dos aspectos sócio-culturais da imagem, poéticas e teorias da arte contemporânea, fotografia e novos meios, metodologia do trabalho de investigação e elaboração do trabalho de conclusão de curso (TCC). Estes foram alguns dos desdobramentos que o currículo anterior não propunha. 
Considero positiva a migração do currículo de Educação Artística para o de Artes Visuais, entendendo o currículo como "documento de identidade" (SILVA, 2002, p.150), que, nesse sentido, forjou minha identidade em torno de questões mais atualizadas para o ensino da arte, abrindo-me a possibilidade de verticalizar aprendizagens e experiências no universo imagético, refletindo e discutindo suas implicações pedagógicas, simbólicas e culturais.

Ressalto que as ausências no currículo também são significativas e contribuem para a compreensão do modo como as identidades são construídas. A nova organização curricular deu pouca ênfase às discussões sobre os processos imagéticos resultantes das imagens técnicas ${ }^{3}$, que, nesse sentido, integrava o currículo somente a disciplina Fotografia e Novos Meios, que objetivava proporcionar um domínio da técnica fotográfica, fato essencial, nesse novo cenário, mas sem reflexões endereçadas ao universo da educação em artes.

De forma similar, discussões referentes às imagens em movimento, em especial as do cinema, não foram contempladas por esse currículo. É importante lembrar que a cinematografia iniciou-se inteiramente visual e, após algumas décadas, integrou o som às imagens, gerando agenciamentos no campo do audiovisual. Não perdeu, todavia, sua natureza imagética, e, dessa forma, seria imprescindível sua inclusão tanto na formação dos docentes de artes visuais como nas práticas educativas escolares. Nessa ordem, os futuros professores que se orientariam em torno das imagens, em suas múltiplas dimensões, sendo que tais discussões abriram caminhos para ampliar as percepções de mundo, por meio do cinema, tevê e internet, por exemplo.

Reflexões sobre o ambiente escolar foram iniciadas, a partir de então, com as disciplinas que estabeleceram interlocuções entre os processos pedagógicos, as relações de ensino e aprendizagem e o universo das artes visuais. Disciplinas como Ensino de Arte e Educação Especial; Arte, Percepção e Aprendizagem; História do Ensino das Artes Visuais no Brasil e Práticas Pedagógicas I, II e III, promoveram ricas aproximações com a escola desde o segundo ano, desse curso.

Ao lembrar as experiências mais significativas e que afetaram minha interação com o mundo estético e do trabalho, percebi que a disciplina Práticas Pedagógicas // contribuiu muito para a maneira como penso os tempos e os espaços escolares e como organizo

\footnotetext{
3 Para Flusser (2002), imagens técnicas são as imagens produzidas por aparelhos. Câmeras fotográficas, filmadoras, telefones celulares, computadores são exemplos de aparelhos que produzem imagens e que devem ser considerados como alternativas educativas para que os estudantes possam perceber, interpretar e representar o mundo em que vivem.
} 
meus processos metodológicos. Para o cumprimento do estágio supervisionado, exigido por essa disciplina, a professora Dra. Irene Tourinho sistematizou uma forma de organizar as práticas pedagógicas a partir de temáticas (Projetos) que atendiam tanto aos temas em discussão nas escolas quanto aos conhecimentos sobre artes visuais, como arte e artistas, arte e corpo, arte e meio ambiente. Esse modo de organização pedagógica foi denominado, por ela, de Unidade Temática de Ensino - UTE.

A UTE consistia na elaboração de sete aulas integradas a uma temática específica, devendo ser formuladas, segundo uma estrutura que se compunha, a partir de objetivos específicos, procedimentos metodológicos, conceitos, palavras-chave e recursos materiais e imagéticos. Desse modo, cada aula era organizada, tendo em vista os conhecimentos artísticos, a partir de novos conceitos, novas palavras-chave e interações imagéticas, tanto na dimensão da compreensão e interpretação crítica quanto na elaboração artística, eram discutidas e reforçavam os conceitos trabalhados, anteriormente, ampliando, portanto, a aprendizagem acerca do universo visual.

Associo essa forma de sistematizar os conhecimentos em arte, proposta pela professora Dra. Irene Tourinho, ao que Burke (2003) definiu como "híbrido", pois a organização da UTE se vinculava, a meu ver, ao pensamento de J. Dewey, no que tange às suas concepções sobre a necessidade da aprendizagem dos conceitos. Referia-se ao ensino das ideias-chave de J. Bruner e, ainda, à importância da imagem para o ensino e para a aprendizagem significativa em artes visuais, proposta por Ana Mae Barbosa.

Outra identificação que delineou minha identidade de professor de arte - que se orienta pelo trabalho pedagógico desenvolvido por temáticas ou projetos - foi que, concomitantemente a esses momentos de aprendizagens sistematizadas e mediadas pelas ações da referida disciplina, eu já trabalhava como professor de arte numa escola da Secretaria Municipal de Educação de Goiânia - SME, no ciclo I, correspondente à “alfabetização, primeira e segunda séries" (SME, 2004, p. 21), da primeira fase do Ensino Fundamental. A organização do tempo e dos espaços pedagógicos, nessa rede de ensino, é estruturada pelo Ciclo de Formação Humana, que estabelece a educação por:

ciclos de formação é uma organização do tempo escolar de forma a se adequar melhor as características biológicas e culturais do desenvolvimento de todos os alunos. Não significa, portanto, 'dar mais tempo para os mais fracos', mas, antes disso, é dar tempo adequado a todos. (SME, 2004, p. 30). 
Uma das características desse desenho escolar é o agrupamento dos estudantes por idade, independentemente das aprendizagens adquiridas, em que se respeita, acima de tudo, os ritmos biológicos. Resultantes da organização do Ensino Fundamental em ciclos de formação surgem problemas como a distonia do aprendizado em relação à série/idade, a transferência e adaptação de estudantes de escolas que são organizadas de outros modos e a não-adoção de notas como pressuposto para o avanço à série seguinte.

Essa escola, em que trabalhei, adotou as concepções do Tema Gerador, ou seja, organizava seu currículo em torno de temas surgidos nos embates dialógicos entre estudantes e professores. A respeito dessa questão, assegura Silva (2004) que os projetos interdisciplinares que se orientam pelo Tema Gerador apoiam-se na “dialogicidade como referência para a construção do currículo e como dinâmica proposta para a vivência das atividades em sala de aula" (p. 122). Visto por outro lado, o Tema Gerador se configura nas falas significativas e, muitas vezes, carregadas de contradições e sensos-comuns dos estudantes sobre a realidade na qual a comunidade escolar está inserida. Desse modo, todas as disciplinas da matriz curricular elencam seus conteúdos específicos para a ampliação das informações denominadas de senso-comum, transformando-as em conhecimentos sistematicamente organizados e refletidos.

Naquele ano, além da experiência com a UTE, desenvolvida na disciplina Prática Pedagógica II, elaborei outras três temáticas sobre arte para a escola. Aquelas experiências contribuíram para a reflexão sobre minhas ações docentes e, transcendendo a visão pragmática, tramaram minha identidade, pois ficam percebidas as identificações profissional, intelectual, cultural, emocional a cada unidade temática de ensino (Projeto) que realizo.

Desde 2003, após ter colado grau, venho trabalhando em duas escolas de periferia em Goiânia, convivendo com realidades diferentes, tanto do ponto de vista estrutural, procedimental quanto conceitual, tendo desenvolvido inúmeras unidades de ensino. Dentre elas, Cemitério Santana: mediando o ensino e a aprendizagem das artes visuais, Aprendendo arte com Tarsila, Siron e Poteiro, Do figurativo ao abstrato: uma experiência com Mondrian entre outras solicitadas pelas escolas. A partir desses trabalhos, acredito que foi possível desenvolver experiências educativas significativas em cada uma dessas realidades.

Um dos espaços em que venho aprendendo a ensinar arte é o da formação continuada, onde tenho me reunido com outros professores no Centro de Estudo e Pesquisa Ciranda da Arte - espaço da rede Estadual de Educação de Goiás, que agrega professores para 
discussão, reflexão e sistematização de experiências desenvolvidas no ensino das artes. Esse lugar, também, tem contribuído com a minha formação identitária, pois me permite desenvolver experiências educativas com professores que ensinam arte nos 246 municípios do Estado de Goiás, refletindo sobre os modos como se aprende e se ensina arte; permite, ainda, que eu coordene as discussões e sistematizações das orientações curriculares para a educação em arte em toda a Educação Básica da Rede Estadual.

Além da Licenciatura em Artes Visuais e das vivências docentes citadas, outra importante experiência que compôs minha trajetória, de aprendizagens sobre como ensinar arte, foi - Mestrado em Cultura Visual, da Faculdade de Artes Visuais/UFG. Inserido na linha de pesquisa Culturas da Imagem e Processos de Mediação, ampliei, significativamente, as possibilidades de interação, significação e interpretação imagética na tríade espectador, professor e investigador.

Enfim, as experiências de aprendizagem referendadas ao Ciranda da Arte e no mestrado são significativas, merecem mais atenção e serão relatadas com maior riqueza de detalhes em outros textos. A seguir, descreverei o colégio onde a unidade de ensino foi desenvolvida, a qual se fundamentou nos aportes teóricos da cultura visual e as razões que motivaram a escolha do videoclipe como objeto de estudo daquele semestre.

\section{A escola, a cultura visual e os videoclipes}

Como me referi, anteriormente, a cada unidade temática de ensino que desenvolvo, os desafios são transformados em possibilidades e novas identificações culturais, são delineadas. Em consonância, enquanto professor de artes visuais no Colégio Estadual Edmundo Rocha, desenvolvi, junto aos estudantes do Ensino Médio, vários conjuntos de aprendizagens que envolviam contextualização, compreensão crítica e produção de imagens fixas e/ou técnicas. Localizado na Região Noroeste de Goiânia, uma das maiores e mais carentes regiões da capital, esse colégio é composto por uma quadra de esportes, dois pavilhões paralelos que abrigam catorze salas de aula, uma biblioteca, sala dos professores, diretoria e secretaria, tudo construído em placas pré-moldadas. Entre os pavilhões há um pátio descoberto, para o qual convergem todas as salas, permitindo, de certo modo, um controle maior da movimentação dos estudantes. 


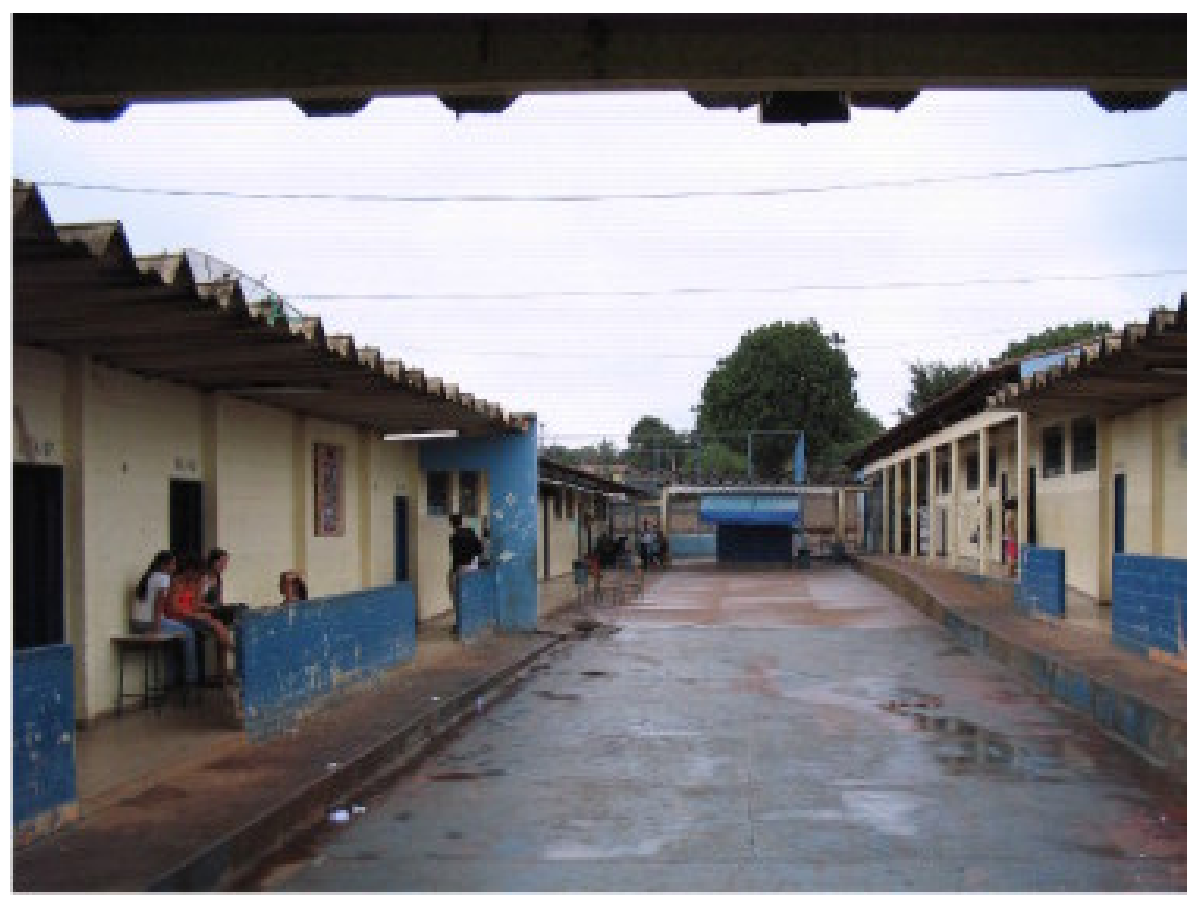

Figura.01 Pátio. Fonte: arquivo pessoal de Henrique Lima Assis

Esse pátio, por ser o maior espaço coletivo, torna-se o ambiente das festividades, das negociações, dos encontros e dos conflitos. Além de arena e palco das relações sociais, é um ambiente que permite enxergar o céu, receber diretamente os raios solares, sentir a brisa da noite e avistar as copas das árvores que circundam a escola pelo lado de fora. É, também, confidente e espectador das diversas relações compartilhadas pelos estudantes, no entanto, quase nunca é utilizado para desdobramentos de atividades pedagógicas ou como espaço para promoção de aprendizagens sistematizadas. Ao longo do tempo, fui percebendo que a comunidade escolar construiu a concepção de que só se aprende, e, consequentemente, se ensina, no interior das salas de aula, com o auxílio dos livros didáticos e do quadro de giz.

Na perspectiva de romper com esses "hábitos enrijecidos" (EISNER, 2008, p. 16), desenvolvi, junto aos estudantes do ensino médio, mais uma unidade temática de ensino, intitulada Olhares eletrônicos: uma experiência com a cultura visual, com vistas ao desenvolvimento de ações que permitissem: a) ampliar as possibilidades de representação, comunicação, modos de olhar, interpretar e compreender tanto as imagens técnicas quanto seus cotidianos; b) utilizar, também, outros espaços dentro e fora da escola para aprender.

Fundamentado na ideia de Sacristán (1995), segundo o qual os desenhos curriculares selecionam, enfatizam, valorizam mais certos elementos em relação a outros, essa 
unidade temática objetivou a compreensão das diferentes noções, usos e semânticas do termo imagem. O desafio maior dessa unidade de ensino, numa escola que, geralmente, transmite respostas únicas e absolutas sobre os conteúdos, encontrou-se delineado pelo entendimento das múltiplas definições e empregos que foram construídos ao longo dos anos em torno das imagens. Diante dessa diversidade de significações, em todas as suas manifestações, as imagens jamais são neutras e sempre representam, apontam ou questionam algo. Nesse cenário, contextualizar, compreender criticamente e produzir videoclipes configurou-se a modalidade ${ }^{4}$ selecionada para o estudo.

Essa unidade temática de ensino estruturou-se de modo que concepções e práticas relacionadas aos videoclipes fossem discutidas e refletidas sob os aportes da Cultura Visual. A cultura visual aparece, assim, como um espaço ou campo de estudo transdisciplinar que se alimenta nos estudos culturais, feministas, cultural material, história cultural da arte, entre outros, e questiona as práticas e os efeitos do olhar, ou seja, como o universo de imagens e artefatos, do passado e do presente, afeta o modo como vemos, como somos vistos e como somos capazes de ver a nós mesmos e ao mundo.

A cultura visual nos permite repensar as bases que orientam a educação das artes visuais e não se trata somente da ampliação dos objetos que podem fazer parte do acervo de estudo. O que ela propõe não é apenas uma questão de objetos, artefatos ou imagens, mas de estratégias para nos relacionar com eles. Assim sendo, a pergunta a responder não é mais o 'que é a cultura visual ou quais são objetos que ela abarca', mas 'o que fala de mim esta representação visual?' Nesta perspectiva, as aproximações com as imagens são mais dinâmicas, pois oferecerem mecanismos que viabilizam informações contidas na memória, na afetividade, nas experiências cognitivas anteriores, na cultura; enfim, na história individual. De modo ativo, os estudantes dialogam, interagem, constroem significados, aprendem e produzem novas imagens.

Ou seja, a cultura visual desloca o papel dos sujeitos que, até então, eram considerados somente receptores para produtores e visualizadores críticos, quebra os posicionamentos hegemônicos sobre as manifestações e as práticas artísticas, explora relações e possibilidades de interpretação e produção que ainda não haviam sido consideradas por outras concepções de ensino de artes visuais.

\footnotetext{
${ }^{4}$ Os diferentes meios ou canais ou suportes ou técnicas ou materiais que geralmente denominam e agregam tipos de imagens são chamados, neste texto, de modalidades. Por exemplo, tecelagem, pintura, escultura, fotografia, videoclipe, cinema.
} 
Não seguindo nenhum líder e nenhuma voz hegemônica, vários professores/pesquisadores de diferentes nacionalidades têm definido a cultura visual como um corpus emergente de saberes que "abordam espaços e maneiras [de] como a cultura se torna visível e o visível se torna cultura" (MARTINS, 2004, p. 160). Para Dias (2005), esse campo de conhecimento se ocupa em estudar o modo como são construídas coletivamente as experiências visuais que movem, assim, "sua atenção das belas-artes ou da cultura de elite para a visualização do cotidiano" (p. 281). Já Ballengee-Morris, Daniel e Stuhr (2005) concebem essa nova área de construção de saberes como sendo o "termo dado à mudança e à compreensão de arte expandida, refletida na Arte/Educação" (p. 264), devido à intensa propagação de imagens e artefatos na atualidade. Para Freedman (2000) a cultura visual

inclui as belas artes, a televisão, o cinema e o vídeo, a esfera virtual, a fotografia de moda, a publicidade, etc. A crescente penetração dessas formas de cultura visual e da liberdade com que elas cruzam os limites tradicionais pode ser apreciada na utilização das belas artes nos anúncios publicitários, na imagem gerada por computador nos filmes e na exposição de vídeos nos museus ( $p$. 316).

Uma característica importante da cultura visual é que ela rompe com a apreciação passiva, estática e suscita uma compreensão crítica "das práticas sociais do olhar e da representação visual, de suas funções sociais e das relações de poder às quais se vincula" (EFLAND, 2004, p. 229). Ainda, as estratégias metodológicas, que propõe a cultura visual, exigem uma mudança tanto nos objetivos quanto na prática das artes visuais, ampliando, desse modo, os temas e conteúdos, e, sobretudo, as “imagens, artefatos, instrumentos e aparatos, bem como a experiência de indivíduos mediados e em rede em um século XXI globalizado" (TAVIN, 2005, p. 17).

Em sintonia com esses pesquisadores, a seleção do videoclipe como objeto de estudo daquele semestre efetivou-se por duas razões. A primeira foi amparada nas reflexões de Hernández (2006), que argumenta que a Cultura Visual pode criar uma aproximação mais rica, mais viva, em que se pode construir um olhar diferente do tradicional, que tem mais relação com a cultura do videoclipe, do instantâneo, da associação, que, na maioria das vezes, os jovens fazem muito bem.

A segunda razão foi decorrente da leitura dos Parâmetros Curriculares Nacionais para o Ensino Médio - PCNEM (1999), os quais orientam sobre a necessidade de ampliação da compreensão, interpretação e produção em suportes bi e tridimensionais, tais como desenhos, pinturas, gravuras, modelagens, esculturas, para "outras manifestações, como as artes audiovisuais" (p. 169). Inserir discussões como essas nos arranjos curriculares 
possibilita aos estudantes interagir, interpretar ou representar outras modalidades como, por exemplo, o cinema de animação, vídeoarte, fotografias, reprografias, ambientes de vitrines, cenários, design, artes gráficas, e o aprofundamento das aprendizagens daqueles que já as utilizam em suas dimensões expressivas e comunicativas.

Neste artigo, portanto, escolhi relatar o modo como fui desenvolvendo as aulas de artes visuais naquele semestre, como fui transformando os desafios em possibilidades. Ressalto também que o modo como tenho construído e desenvolvido as diferentes unidades temáticas de ensino encontra-se fortemente marcado pelas experiências vividas na disciplina Práticas Pedagógicas II, que promoveu intensos debates sobre a possibilidade de ensinar e aprender a arte a partir de temáticas variadas que atendessem aos interesses da escola, porém, sobretudo, dos estudantes.

Hall (2005) esclarece, nessa direção, que as identidades culturais na pós-modernidade são "formada[s] e transformada[s] continuamente em relação às formas pelas quais somos representados ou interpelados nos sistemas culturais que nos rodeiam" (p. 13). Assim sendo, alguns anos se passaram, outras experiências pedagógicas pude desenvolver, outras leituras e referenciais marcaram e têm marcado minha identidade profissional. Nesse contexto, a unidade temática de ensino Olhares eletrônicos: uma experiência com a cultura visual ressalta que as identificações são fluidas, móveis, transformam-se continuamente, mas não abandonam a compreensão de que todos os processos humanos, qualquer um deles, exigem alguma constância, pois a história se apresenta com suas pregnâncias e permanências, carregando para o presente a tradição, sempre mutável, mas, mesmo assim, se constitui ponto de partida para as novas, múltiplas e possíveis identificações.

Entendendo que a história se apresenta com suas permanências e rupturas, que carrega para o presente a tradição, sempre mutável, mas, também, é ponto de partida para as novas identificações, neste artigo, fiz a opção por apresentar as reflexões apenas do modo como organizei as aulas da unidade temática de ensino denominada Olhares eletrônico: uma experiência com a cultura visual e estabelecer relações com minhas aprendizagens na licenciatura. Estas reflexões e relações serão apresentadas no tópico que se segue.

\section{Narrativas de ensinar}

Compactuo com a concepção de que somos transformados continuamente pelos sistemas que nos circundam, então, a experiência como estudante do Programa de Mestrado em Cultura Visual contribuiu, significativamente, para com minhas poéticas pedagógicas. Sendo assim, passei a interagir melhor com os espaços e os modos pelos quais as 
culturas são representadas e as representações se tornam culturas, e, consequentemente, meu repertório imagético ampliou-se, possibilitando-me ampliar também o repertório de meus estudantes.

As ações que estruturaram as vinte aulas $^{5}$ da unidade temática de ensino mencionada foram subdivididas em quatro blocos integrados e compostos por objetivos, conceitos e palavras-chave, recursos materiais e imagéticos. Essas características, fruto das aprendizagens da disciplina Práticas Pedagógicas II, conforme mencionei, são pontos recorrentes e abertos a múltiplas identificações profissionais. Nesta direção, o primeiro bloco de aulas foi destinado à discussão das diferentes concepções sobre o termo imagem. Selecionei, para a primeira aula, alguns álbuns com inúmeras reproduções de imagens artísticas, publicitárias, religiosas, familiares, de diferentes suportes, técnicas e materiais. Em grupo ${ }^{6}$, os estudantes deveriam observá-las, escolhendo dez para agrupar em torno de um tema e, no final do encontro, apresentar tanto as imagens quanto as justificativas para o tema escolhido. Houve agrupamentos que representavam partes do corpo, fotografias de cidades ou motivações religiosas.

Na aula seguinte, preparei uma fala a partir das obras: a) Filosofia da caixa preta: ensaios para uma futura filosofia da fotografia de Vilém Flusser (2002) e b) Dicionário teórico e crítico de cinema de Jacques Aumont e Michel Marie (2003). Pautei as interlocuções no entendimento de que as imagens são superfícies que almejam representar 'coisas' que, geralmente, se encontram fora no espaço e no tempo. "As imagens são, portanto, resultado do esforço de se abstrair duas das quatro dimensões de espaço tempo, para que se conservem apenas as dimensões do plano" (FLUSSER, 2002, p. 07).

Flusser (2002, p. 07) acrescenta, ainda, que imagens são "códigos que traduzem eventos em situações, processos em cenas. Não que as imagens eternalizem eventos; elas substituem eventos por cenas". Sendo assim, as visualidades são mediações dos homens e mulheres com o mundo. Enfim, "as imagens têm o propósito de representar o mundo. Mas ao fazê-lo, interpõem-se entre o mundo e o homem" (p. 09). Nessa perspectiva, Flusser entende que os sujeitos se forjam, culturalmente, a partir das relações mediadas pelas imagens, evidenciando que elementos simbólicos são operados tanto na produção

\footnotetext{
${ }^{5}$ É contemplada apenas uma aula de arte por semana na matriz curricular do Ensino Médio em Goiás, desse modo, vinte aulas equivalem a um semestre letivo.

${ }^{6}$ Os grupos formados nessa aula deveriam permanecer juntos, para desenvolver todas as atividades, até o fim da unidade temática de ensino.
} 
quanto na interpretação e compreensão das imagens e da cultura sobre a qual se inserem ou interagem.

Ao desdobrar o conceito e as abrangências sobre a imagem, Aumont e Marie (2003) comentam acerca da variedade de classificações que o termo pode alcançar. Eles começam informando que as imagens "se dirigem, notadamente, a nossos diversos sentidos (imagens visuais, auditivas, táteis, olfativas, etc.)" (p. 160), ou seja, as sensações acompanhadas de ideias são rotuladas como "imagem mental". Em seguida, divergindo de Flusser, para quem as imagens representam algo, Aumont e Marie (2003) referem-se, também, às imagens produzidas a partir de fenômenos naturais, citando o "reflexo, sombra, visão através de um corpo transparente etc" (p.160).

Nas concepções de Aumont e Marie, esses fenômenos são "multiformes, e que, notadamente, seu vínculo com a noção de representação, a fortiori com a de analogia, é bem variável" (Idem). Sendo assim, suas anotações são confirmadas a partir da observação da arte do século XX e da presença de "muitas imagens não representativas: o que se chama de 'pintura abstrata'" (Idem). Outras definições são apresentadas pelos autores, variando seus empregos e relações, por exemplo, "imagem-ação", "imagemafecção", “imagem-percepção", “imagem-pulsão" e “imagem-tempo" são variações que dizem respeito às imagens técnicas. Essas variações, na experiência em questão, tiveram o objetivo de desestabilizar, pelo menos em parte, a cultura da escola em transmitir respostas únicas e absolutas sobre um conteúdo.

Encerrando o primeiro bloco de discussão e iniciando o segundo, propus aos grupos de estudantes o desafio de encontrarem definições que contextualizassem o videoclipe no Brasil, sua origem e função e, ainda, apresentassem, para os colegas, um clipe que tivesse sintonia com a temática escolhida na primeira aula. Para apresentação e discussão de todos os grupos foram necessárias três aulas. Para além das definições dos videoclipes, como produtos audiovisuais com funções predominantemente comerciais ligados ao universo musical, foi possível fechar as discussões compreendendo a pluralidade de sentidos e significados que atravessa essas visualidades e que questiona sua complexa natureza, suas fronteiras, por exemplo, com a videoarte e com o curtametragem.

O terceiro bloco de estudos foi destinado à produção dos videoclipes. Essa etapa da aprendizagem consistiu-se nas seguintes atividades: a) escrita do roteiro; b) escolha da música; c) captura das imagens; d) entendimento do funcionamento do programa de edição de imagens Windows Movie Maker e e) edição dos videoclipes. Essa fase teve a duração de 12 aulas, pois o tempo e ritmo de aprendizagens de cada grupo relacionado 
ao programa de edição foram diversos. Alguns grupos eram compostos por estudantes que conheciam bem o programa e até outros, como, por exemplo, Adobe Premier e Adobe After Effects. No planejamento inicial, destinei uma aula para escrita do roteiro e outra para a seleção da música, mas todas essas ações foram resolvidas na primeira aula.

Com o roteiro em mãos, o passo seguinte foi sair da sala de aula para capturar as imagens. Os grupos se dividiram, e alguns estudantes, com suas câmeras digitais ou aparelhos celulares em punho, andavam pelo pátio da escola ou pelas ruas do bairro fotografando e os outros foram para a lan hause, em frente à escola, para acessarem a internent, em busca de mais visualidades para elaborarem seus clipes. Como a escola ainda não possuía laboratório de informática, a lan hause foi de extrema importância para o desenvolvimento do Olhares Eletrônicos. Por meio de um acordo com o proprietário, cada estudante pagaria $\mathrm{R} \$ 0,50$ centavos por aula, tanto para usar a internet quanto para aprender a manipular e editar os vídeos.

Essa etapa do trabalho tinha como primeiros desafios e destabilizações: atravessar a avenida, ligar os computadores e iniciar a construção das narrativas. I mportar tanto as imagens das câmeras ou dos aparelhos celulares ou copiadas da internet quanto a música selecionada; escolher os efeitos, por exemplo, de acelerar, afastar, aproximar, ampliar, girar, panorâmica de cima para baixo ou de baixo para cima, tons de sépia, todo o espectro de cores ou tudo de uma vez; foram experiências de ver e olhar ${ }^{7}$ que seduziram os iniciados. Além do prazer de brincar com as inúmeras possibilidades de transições de uma imagem para a outra, havia a dor de selecionar a que melhor se adequava ao roteiro. Mais um conflito! Inserir o título e os créditos, nome de quem apareceria como diretor, fotógrafo, editor, todos os nomes em todas as funções, "pois no nosso grupo todos fizeram tudo", sugere uma estudante. Publicar em DVD e esperar ansiosamente pela próxima aula para assistir o seu e o trabalho dos colegas, ao som das músicas e comendo pipoca.

Como a cultura visual não trata somente da ampliação dos objetos que podem fazer parte do acervo de estudo, mas de desenvolver estratégias para nos relacionar com eles,

\footnotetext{
${ }^{7}$ A filósofa Márcia Tiburi (2009) no texto Aprender a pensar é descobrir o olhar pontua que, para além das distinções semânticas, o ato de ver está implicado ao sentido físico da visão enquanto o olhar procura pelo invisível do objeto. Nesta direção, costuma-se "usar a expressão olhar para afirmar uma outra complexidade do ver. Quando chamo alguém para olhar algo espero dele uma atenção estética, demorada e contemplativa, enquanto ao esperar que alguém veja algo, a expectativa se dirige à visualização, ainda que curiosa, sem que se espere dele o aspecto contemplativo. Ver é reto, olhar é sinuoso.Ver é sintético, olhar é analítico. Ver é imediato, olhar é mediado. A imediaticidade do ver torna-o um evento objetivo. Vê-se um fantasma, mas não se olha um fantasma" (p. 01).
} 
deslocar o papel dos sujeitos concebidos como receptores para produtores e visualizadores críticos, descentrar hegemonias sobre as práticas artísticas e explorar as possibilidades de interpretação e produção que algumas abordagens educativas em artes visuais ainda não haviam desenvolvido. Desse modo, o desafio do último bloco de estudos foi interagir com os videoclipes na perspectiva de desenvolver e ampliar os olhares tanto sobre as produções elaboradas quanto sobre o mundo e sobre os sujeitos que elas representaram.

O que os clipes falam ou não falam de mim, estudante do ensino médio, jovem, trabalhador ou trabalhadora, consumidor ou consumidora? Quais relações com outros aspectos da cultura os videoclipes me permitem estabelecer? Quais memórias e/ou projetos de futuro eles acionam? O objetivo central, nessas aulas, foi estabelecer um ambiente propício para diálogos e reflexões sobre temas relacionados à religiosidade, à sexualidade, à juventude, às relações de poder e à arte que foram vinculados às narrativas visuais elaboradas pelos estudantes, estimulando-os a posicionarem-se criticamente sobre os dilemas morais, sociais e éticos que afligem e demandam a atenção das sociedades contemporâneas.

\section{Por ora concluo que}

Nesse exercício de escrita autobiográfica dos processos que vivenciei, pude, por meio das lembranças dos lugares onde convivi e dos trajetos que percorri, tomar consciência de minhas identificações. Os espaços escolares onde passo a maior parte do meu tempo, além de forjarem minha identidade artística, elaboram, também, as identificações sobre que profissional quero e posso ser. Nesta direção, amparado conceitualmente em Hall (2005), Dubar (1997), Nóvoa (1992) e em outros pesquisadores, compreendo que além das pregnâncias e permanências que configuram o meu "ser" e "estar" no mundo, não estou pronto e acabado, movo-me sempre, traduzindo ou reinterpretando ou bricolando os diferentes "ritos", individuais e/ou coletivos, pelos quais, a cada instante, sou iniciado.

Como as identificações são, concomitantemente, processos individuais e coletivos, ao pensar a educação, Hernández (2007) sinaliza que é necessário abordar os estudos da cultura visual não apenas como uma disciplina, ou perspectiva, mas como uma possibilidade de subverter fronteiras, ampliar debates e criar novas relações conceituais e pedagógicas com o mundo das imagens e artefatos culturais, enfim, construir outra narrativa para a educação das artes visuais. Nessa direção, as ações e diálogos produzidos em Olhares eletrônicos: uma experiência com a cultura visual, apesar de tímidos, indicam que se desenvolve o olhar rompendo com o sentido físico do ato de ver, olhando sinuosa e atentamente, percebendo e analisando as nuances, compreendendo e construindo significados, questionando hegemonias e relatos discursivos pré-fixados a 
partir do universo imagético dos videoclipes mediado pelas aulas de artes visuais, ao levar estudantes a posicionarem-se criticamente sobre os dilemas morais, sociais e éticos que afligem e demandam a atenção das sociedades contemporâneas e, também, transformar a função reprodutora que atualmente a escola insiste em manter.

\section{Referências}

AGIER, Michel. Distúrbios identitários em tempos de globalização. Mana, v. 7, n. 2, 2001.

AUMONT, Jacques e MARIE, Michel. Dicionário teórico e crítico de cinema. Tradução: Eloísa Araújo Ribeiro. Campinas, SP: Papirus, 2003.

BALLENGEE-MORRIS, Christine, DANIEL, Vesta A. H. STUHR, Patricia L. Questões de diversidade na Educação e Cultura Visual: comunidade, justiça social e pós-colonialismo. In: BARBOSA, Ana Mae. (Org) Arte / Educação Contemporânea - consonâncias internacionais. Barbosa. São Paulo: Cortez, 2005.

BARBOSA, Ana Mae. (Org.). Ensino da arte: memória e história. São Paulo: Perspectiva, 2008.

BENJ AMI M, Walter. Sobre o conceito de história. São Paulo: Rouanet, 1996.

BOSI, Eclea. Memória e Sociedade: lembranças de velhos. São Paulo: Companhia das Letras, 2007. 484p.

BURKE, Peter. Hibridismo cultural. Tradução: Leila Souza Mendes. São Leopoldo, RS: Editora UNISINOS, 2003.

BRASIL, Ministério da Educação. Secretaria de Educação Média e Tecnológica. Parâmetros curriculares nacionais: ensino médio. Brasília, 1999.

DIAS, Belidson. Entre Arte/Educação multicultural, cultura visual e teoria queer, In: BARBOSA, Ana Mae. (Org) Arte / Educação Contemporânea - consonâncias internacionais. Barbosa. São Paulo: Cortez, 2005.

DUBAR, Claude. A socialização: construção das identidades sociais e profissionais. Porto: Porto Editora, 1997. 
EFLAND, A. Educación artística y cognición. Barcelona: Octaedro, 2004.

EISNER, Elliot. O que pode a educação aprender das artes sobre a prática da educação? In: Currículo sem Fronteiras, v.8, n.2, pp.5-17, Jul/Dez 2008.

FLUSSER, Vilém. Filosofia da caixa preta: ensaios para uma futura filosofia da fotografia. Rio de Janeiro: Relume Dumará, 2002.

FREEDMAN, Kerry. Social perspectivas on art education in the U. S.: teaching visual culture in a democracy. Studies in Art Education, 41 (4), p. 314-329, 2000.

GOIÂNIA, Secretaria Municipal de Educação. Algumas concepções que orientam a educação da infância e da adolescência na RME. In: Proposta político-pedagógica para a educação fundamental da infância e da adolescência. Goiânia: Grafset, 2004. 112p.

HALL, Stwart. A identidade cultural na pós-modernidade. Rio de Janeiro: DP\&A, 2005.

HERNÁNDEZ, Fernando. Olhar eletrônico. O Popular, Goiânia, 23 de outubro de 2006. Magazine, p. 01.

HERNÁNDEZ, Fernando (2007) Catadores da cultura visual. Proposta para uma nova narrativa educacional. Porto Alegre (Brazil): Editora Mediação.

LE GOFF, Jacques. História e memória. Campinas: Editora da Unicamp, 1996. 248p.

MARTINS, Raimundo. Cultura Visual: imagem, subjetividade e cotidiano. In: MEDEIROS, Maria Beatriz de. (org). Arte em pesquisa: especificidades. Ensino e Aprendizagem da Arte; Linguagens Visuais. Brasília, DF: Editora da Pós-graduação em Arte da Universidade de Brasília, 2004. v. 2.

NÓVOA, Antônio. Os professores e suas histórias. In: NÓVOA, Antônio. Vidas de Professores. Porto: Porto Editora, 1992. 216p.

SACRISTÁN, José Gimeno. Currículo e diversidade cultural. In: SILVA Tomaz. T. \& MOREIRA Antonio F. (Org.). Territórios contestados - O currículo e os novos mapas políticos culturais. Petrópolis: Vozes, 1995. 
SANCHIS, Pierre. A crise dos paradigmas em antropologia. In: DAYRELL, Juarez (Org.). Múltiplos olhares sobre educação e cultura. Belo Horizonte: Editora UFMG, 1996. $194 p$.

SILVA, Antônio Fernando Gouveia da. A construção do currículo na perspectiva critica: das falas significativas às praticas contextualizadas. Tese de Doutorado, SP, PUC, 2004.

SILVA, Tomás Tadeu. Documentos de identidade: uma introdução às teorias do currículo. Belo Horizonte: Autêntica, 2002. 154p.

TAVIN, K. Opening re-marks. Critical antecedents of visual culture in art education. Studies in Art Education, n. 47 (I), 2005, p. 5-22.

TIBURI, Márcia. Aprender a pensar é descobrir o olhar. Disponível em: ihttp://hêlamor.multiply.com/journal//item/13zä. Acesso em 08/06/2009.

WOODWARD, Kathryn. Identidade e diferença: uma introdução teórica e conceitual. In: SILVA, Tomás Tadeu. (org.). I dentidade e diferença - a perspectiva dos estudos culturais. Petrópolis, RJ: Editora Voses Ltda, 2006. 133p. 